\title{
Relapsing and remitting insulin requiring diabetes: type 1 or type 2 ?
}

\section{Candy Sze ${ }^{1}$ Diane Gould ${ }^{2} \quad$ Graham Hitman ${ }^{3}$ Tahseen A Chowdhury ${ }^{3}$}

J R Soc Med 2006;99:415-416

We present a case of ketosis prone type 2 diabetes - an unusual presentation of diabetes seen predominantly in African-Caribbean patients.

\section{CASE HISTORY}

A 28-year-old previously healthy Barbadian man presented in May 1998 with acute polyuria, polydipsia and weight loss of approximately $4 \mathrm{~kg}$. He was dehydrated, and his random plasma glucose was $21 \mathrm{mmol} / \mathrm{L}$, with ++ ketonuria and arterial pH 7.24 (normal range 7.35-7.45). He was treated for diabetic ketoacidosis, with intravenous fluids and insulin and, subsequently, subcutaneous twice daily mixtard 30 insulin, 15 units twice daily. Anti-islet cell antibodies were negative. He remained on this dose for about 4 months after diagnosis, but was subsequently troubled by frequent hypoglycaemia. Thereafter, he took insulin intermittently for a year. Despite prolonged periods without any insulin, he did not develop ketoacidosis. He failed to attend follow up in the diabetes clinic; but by early 2000 he was taking no insulin. In January 2003, he underwent an oral glucose tolerance test for an employment medical, which showed fasting glucose $5.5 \mathrm{mmol} / \mathrm{L}$, and 2-hour glucose $3.7 \mathrm{mmol} / \mathrm{L}$.

He remained well until he was referred to the diabetic clinic by his practice nurse in June 2004. He presented with 2 weeks of dizziness, polyuria, thirst and polydipsia. Capillary blood glucose was $26 \mathrm{mmol} / \mathrm{L}$, with +++ glucosuria and ++ ketonuria. Random plasma glucose was $30.2 \mathrm{mmol} / \mathrm{L}$, and glycated haemoglobin (HbA1c) 12.6\% (normal range 4.8-6.4\%). He was recommenced on twice daily novomix 30 insulin, 15 units twice daily. On review 4 weeks later the patient had reduced his insulin dose due to recurrent hypoglycaemia. Self monitoring of capillary glucose showed levels between 3-7 mmol/L. He had made some changes to his diet, but overall ate healthily and did

${ }^{1}$ Specialist Registrar, ${ }^{2}$ Specialist Practice Nurse, ${ }^{3}$ Consultant in Diabetes, Department of Diabetes and Metabolism, The Royal London Hospital, London, UK

Correspondence to: Dr TA Chowdhury

E-mail: Tahseen.Chowdhury@bartsandthelondon.nhs.uk regular exercise. He did not smoke tobacco, but took occasional cannabis, and rarely drank alcohol. He had no other symptoms of note. Examination showed he was well, not Cushingoid, euthyroid, obese (BMI $34.8 \mathrm{~kg} / \mathrm{m}^{2}$ ), blood pressure $110 / 70 \mathrm{mmHg}$ and had no evidence of neuropathy, retinopathy or vascular disease.

Plasma glucose was $6.5 \mathrm{mmol} / \mathrm{L}$ and $\mathrm{HbA1c} 6.4 \%$. Anti-glutamic acid decarboxylase and islet cell antibodies were negative. Biochemical profile, blood count and thyroid function were normal. His insulin dose was reduced to 16 units daily, and within 4 weeks he had stopped the insulin completely. Self monitoring of blood glucose remained 3-6 mmol/L off insulin. He declined repeat glucose tolerance testing.

He was re-referred to the diabetes clinic in November 2005 with symptomatic hyperglycaemia, random glucose $25.3 \mathrm{mmol} / \mathrm{L}, \mathrm{HbA} 1 \mathrm{c} 11.0 \%$ and ++ketonuria, but with a normal venous bicarbonate $(29 \mathrm{mmol} / \mathrm{L})$. The patient wished to avoid insulin therapy, and we commenced him on repaglinide, a prandial glucose regulator, $2 \mathrm{mg}$ three times daily with meals. Self monitoring of blood glucose has shown moderate control with glucose levels between 6-9 $\mathrm{mmol} / \mathrm{L}$ fasting, and $8-11 \mathrm{mmol} / \mathrm{L}$ post prandially, with good symptomatic relief. HbA1c has improved to $8.2 \%$.

\section{DISCUSSION}

We describe a case of a patient presenting with diabetic ketoacidosis, whose diabetes remitted and relapsed on two further occasions - one of which required insulin. The patient subsequently achieved reasonable glycaemic control with diet and tablets. This case illustrates the occasional difficulty in distinguishing between type 1 and type 2 diabetes (Box 1).

This case exhibits the classical findings of a relatively uncommon type of diabetes, predominantly described in people of African origin. The condition was first described in 1985, ${ }^{1}$ and has many synonyms, including Flatbush, J-type, type $1 \frac{1}{2}$, type 3 , atypical, phasic insulin dependent and ketosis prone type 2 diabetes. $^{2-4}$ The World Health Organization and the American Diabetes Association classify this type of diabetes as idiopathic type 1 diabetes, or type 1B'. ${ }^{5}$ Some authors, however, suggest that 'ketosis prone type 2 diabetes' is a more useful term to describe this cohort of patients. ${ }^{6,7}$

This form of diabetes has similarities with type 1 and type 2. It is characterized by episodic ketosis, without immunological markers of type 1 diabetes, insulin dependence at the time of diagnosis (as seen in type 1 diabetes), but subsequent lack of insulin requirement, frequently for years (as seen in type 2 diabetes).

The most extensive study of the condition has been performed by investigators in Paris. ${ }^{6}$ They followed 233 


\section{Box 1 Learning points}

- Differentiation between type 1 and type 2 diabetes can be difficult in certain circumstances, but is of great clinical importance

- Presence of anti-glumatic acid decarboxylase (GAD) or islet cell antibodies (ICA) supports the diagnosis of type 1 diabetes. Note: these are not always present

- People of African-Caribbean origin may develop acute insulin deficiency leading to diabetic ketoacidosis, but may recover $\beta$ cell function such that insulin is no longer necessary

- Ketosis-prone type 2 diabetes tends to relapse, and many patients become insulin requiring within 5 years

- This form of diabetes is important to recognize as it can have significant implications for treatment of the condition.

patients diagnosed with diabetes in sub-Saharan Africa over a period of 10 years, defining ketosis-prone type 2 diabetes as new-onset diabetes without precipitating cause (infection, stress) with the presence of ketonuria (urine ketones $>80 \mathrm{mg} / \mathrm{dL}$ ) or diabetic ketoacidosis, in the absence of glutamic acid decarboxylase or islet cell autoantibodies. They found a $90 \%$ relapse rate for patients with ketosis prone type 2 diabetes, of whom about $50 \%$ became insulin dependent. There was a demonstrable reversible $\beta$-cell dysfunction, with prolonged normal insulin secretion following a bout of insulin deficiency. The subsequent progressive $\beta$-cell dysfunction seen in such patients is similar to that seen in patients with type 2 diabetes, such that many require insulin after a number of years.

What causes the initial $\beta$-cell insult leading to acute insulin deficiency is unclear. Glucose toxicity has been suggested as a contributing factor, and indeed ketotic relapses have been shown to be preceded by progressive mild hyperglycaemia. ${ }^{8}$ Restoration of normoglycaemia rapidly leads to improvement in $\beta$-cell function, suggesting a causative role of glucose toxicity in $\beta$-cell failure. Obesity is also associated with relapse, suggesting a role for insulin resistance. It is suggested that an inherited predisposition to glucose toxicity or oxidative stress may lead to ketosis prone type 2 diabetes; indeed, low glucose- 6 phosphate dehydrogenase activity, an enzyme active against oxidative stress, is noted in patients with the ketosis prone type 2 diabetes. ${ }^{9}$ More recently, a genetic variation in the PAX4 gene, which is a transcription factor essential in the early development of pancreatic $\beta$-cells, has been shown in patients with this form of diabetes. ${ }^{10} \mathrm{~A}$ specific variant of this gene is seen more frequently in ketosis prone type 2 diabetes, suggesting a possible pathogenic role.

Our patients' most recent presentation is unusual as, despite significant hyperglycaemia and some ketosis, he did not develop acute $\beta$-cell failure, requiring insulin therapy. Nevertheless, his glycaemic control is only moderate on a medium dose of oral hypoglycaemic agent; it is likely that insulin therapy will be required soon to achieve good glycaemic control. In summary, therefore, the description is of a case of relapsing and remitting insulin-requiring diabetes in a Caribbean man, who displays clinical findings typical of both type 1 and type 2 diabetes. It is important for clinicians dealing with patients from African or Caribbean ethnic groups to recognize this relatively uncommon clinical presentation of diabetes.

Competing interests None declared.

\section{REFERENCES}

1 Winter ME, Maclaren NK, Riley WJ, Clarke DW, Kappy MS, Spillar RP. Maturity onset diabetes of youth in black Americans. N Engl J Med 1996; 316: 285-91

2 Monaldo M, Hampe CS, Gaur LK, et al. Ketosis prone diabetes: dissection of a heterogenous syndrome using an immunogenetic and $\beta$ cell functional classification, prospective analysis and clinical outcomes. $J$ Clin Endocrinol Metab 2003;88:5090-8

3 McFarlane SI, Chaiken S, Hirsch P, Harrington P, Lebovitz HE, Banerji MA. Near normoglycaemic remission in African-Americans with type 2 diabetes mellitus is associated with recovery of beta cell function. Diabet Med 2001:18:10-16

4 Ahren B, Corrigan CB. Intermittent need for insulin in a subgroup of diabetic patients in Tanzania. Diabet Med 1985;2:262-4

5 Expert Committee on the diagnosis and classification of diabetes. Diagnosis and classification of diabetes mellitus. Diab Care 2003;26: 3160-7

6 Mauvais -Jarvis F, Sobngwi E, Porcher R, et al. Ketosis-prone type 2 diabetes in patients of sub-saharan African origin. Clinical pathophysiology and natural history of $\beta$-cell dysfunction and insulin resistance. Diabetes 2004;53:645-53

7 Sobngwi E, Gautier JF. Adult onset idiopathic type 1 or ketosis prone type II diabetes: evidence to revisit diabetes classification. Diabetologia 2002;45:283-5

8 Sobngwi E, Vexiau P, Levy V, et al. Metabolic and immunogenetic prediction of long term insulin remission in African patients with atypical diabetes. Diabet Med 2002:19:832-5

9 Sobngwi E, Gautier JF, Kevorkian JP, et al. High prevalence of glucose-6-phosphate dehydrogenase deficiency without gene mutation suggests a novel genetic mechanism predisposing to ketosis-prone diabetes. J Clin Endocrinol Metab 2005;90:4446-51

10 Mauvais-Jarvis F, Smith SB, Le May C, et al. PAX4 gene variation predispose to ketosis-prone diabetes. Hum Mol Genet 2004;13:3151-9 